\title{
A Strength Design Method of Cemented Backfill with a High Aspect Ratio
}

\author{
Zhi-zhihui Wang $\mathbb{D D}^{1,2}$ Ai-xiang $\mathrm{Wu}^{1,2}$ and Hong-jiang Wang ${ }^{1,2}$ \\ ${ }^{1}$ School of Civil \& Resources Engineering, University of Science \& Technology Beijing, Beijing 100083, China \\ ${ }^{2}$ Key Laboratory of High-Efficient Mining and Safety of Metal Mines of the Ministry of Education, \\ University of Science \& Technology Beijing, Beijing 100083, China \\ Correspondence should be addressed to Zhi-zhihui Wang; chihui_w@hotmail.com
}

Received 6 September 2019; Accepted 17 January 2020; Published 19 February 2020

Academic Editor: Paolo Castaldo

Copyright (c) 2020 Zhi-zhihui Wang et al. This is an open access article distributed under the Creative Commons Attribution License, which permits unrestricted use, distribution, and reproduction in any medium, provided the original work is properly cited.

\begin{abstract}
To calculate the required strength of a cemented backfill with high aspect ratio, the confirmation of lateral pressure is fundamental and needs to be determined first. As for the backfill with a high aspect ratio of height to length, the shape of the slip surface is not straight when in the active state due to the limited space, which is different from the general backfill. For this reason, a formulation of the slip surface with a curved shape and a lateral pressure calculation method based on this curved slip surface were proposed. The proposed equation of the slip surface is affected by the geometry parameters of the backfill, internal friction angle of the backfill, and the friction angle of the backfill-rock interface. Then, by the combination of the minor principal stress trajectory method and the horizontal slice method, an ordinary differential equation of stresses was established and then solved numerically. Finally, the method based on Mitchell's three-dimensional limit equilibrium model was used to calculate the required strength of the cemented backfill. The calculated results were compared with previous studies and validated with numerical models. The results showed good consistency for the backfills with high aspect ratios.
\end{abstract}

\section{Introduction}

Cemented backfill mining is widely used to deal with tailings efficiently and ensure safety of underground stopes $[1,2]$. The performance of the cemented backfill is influenced by many factors (such as cement type, addition of reinforcement, loading rate, multiphysical consolidation process [3-5], chemical shrinkage, and temperature) after its placement. And all these factors can influence the stability of the cemented backfill. But, from the mechanical view, the effects of these factors can all be combined in the strength parameters of cohesion and friction angle. Besides that, the backfill-rock interface is also important. Due to the roughness of the rock face $[6,7]$, the cohesion and friction developed at the backfill-rock interface function as shear resistance preventing the failure of the backfill $[8,9]$. Considering the common two-step mining method of extracting and then backfilling, the cemented backfill body of first-step stope will have a free face when extracting the second-step stope. In a series of methods for designing the required strength of the filling body by the limit equilibrium method, the shear resistance force from lateral rock mass is a major concern in the process of evaluating the stability of the backfill body [10-12]. Thus, the lateral pressure force which contributes to the friction resistance has an important influence on the safety factor of the backfill body.

After determining the cohesion and friction angle of the backfill-rock interface, how to determine the lateral pressure force of the filling body remains an important problem. The product of the pressure force and the friction coefficient of the backfill-rock interface is part of shear resistance force preventing the filling body from sliding to the open space. Overestimating this pressure can lead to overestimation of the stability of the filling body, which may result in a lower strength of the backfill. This may pose a potential hazard, such as the collapse of the backfill to the adjacent mining 
area, the liquidation resulted by the insufficiency of strength of the backfill, and the collapse of barricade. Ting et al. [13] simulated the backfilling body of vertical and inclined stope through laboratory experiments and considered that the earth pressure calculated from the active earth pressure state is closer to the experimental results compared with the static earth pressure state. Sobhi et al. [14] also pointed out that when calculating the lateral pressure, the active earth pressure state is more practical than the static earth pressure state which assumes a very large stiffness of the surrounding rock. The calculation of the lateral pressure of the filling body by taking the active earth pressure state is also adopted in $[7,11,14]$. There are two kinds of slip surface when calculating the design strength of the cemented backfill. One is the slip surface used to determine the pressure on the lateral rock. Another is the slip surface used for calculating the safety factor of the cemented backfill when in the limit equilibrium state. And these two are different.

However, in the abovementioned literature, the lateral pressure of the filling body is calculated based on the linear slip surface. In fact, for the filling body with high aspect ratio (the ratio of the height of free face to the length of free face $>\tan \left(45^{\circ}+\varphi / 2\right)$ ), Rankine's slip surface (namely a straight face with an inclination angle of $\pi / 4+\varphi / 2$ ) cannot develop under active earth pressure state, and often a curved slip surface will occur [15-19]. In the case where a linear slip surface cannot be developed, how to obtain a usable lateral pressure force calculation method remains a very important problem. Thus, this paper focuses on the rarely studied backfills with high aspect ratios. The core objective of the present study is to develop a strength design method for cemented backfills with high aspect ratios. To achieve this, a suitable calculation method for the lateral pressure of the filling body with high aspect ratio is required first. And then, a strength design formula for filling body in this case is developed.

\section{Calculation of Lateral Pressure Force}

As shown in Figure 1, a vertical backfill with geometric sizes of $L_{b} \times W \times H$ is considered. The physical experiments performed by Mitchell et al. [20] showed that the sliding body is a wedge on the slip surface when the filling body is unstable. And the backfill-rock pressure is the lateral pressure of the filling body in the unstable state. As mentioned above, the two-dimensional active earth pressure model is generally used to calculate the lateral pressure. The monitored data showed that the earth pressure distribution at the midline and the edge is very close $[16,21]$, so the determined earth pressure is generally considered to be the earth pressure distribution along the midline of lateral face. Moreover, for conservative design and simplicity, it is generally considered that the filling body is cohesionless when calculating the side pressure [12]. In fact, the difficulty in calculating earth pressure of cohesive filling is the same as that of a cohesionless one and can be eliminated by the translation of the normal stress coordinate of the Mohr stress circle.

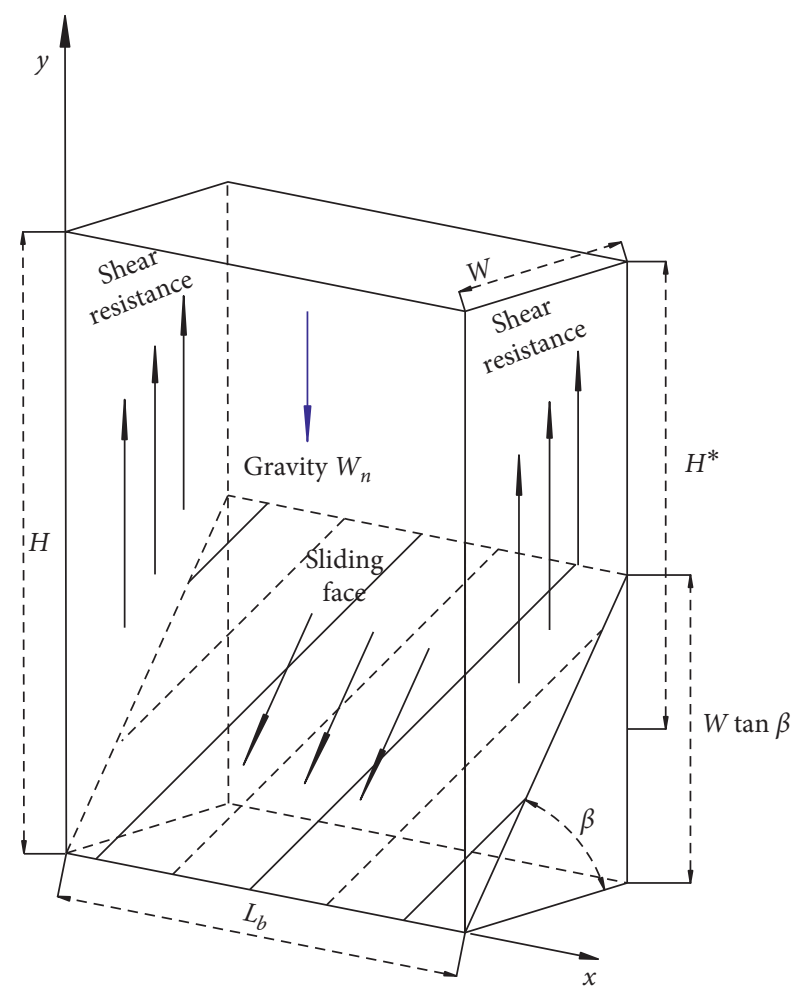

FIGURE 1: Schematic diagram of limit equilibrium analysis of the filling body.

2.1. Determination of the Shape of the Slip Surface. The formulation of a curved slip surface involves the specific geometry of the filling body, which means that it is more targeted to the filling body and closer to the actual situation. However, the disadvantage is that it needs to be calculated for each project, and the formulation of the curved slip surface is more complex than that of a straight line resulting in difficulty to obtain an analytical solution for earth pressure distribution. But, with the development of numerical calculation methods, it is very easy to numerically solve out the earth pressure. Therefore, using a curved slip surface to calculate the lateral pressure should be considered as a refined design method.

The slip surface shown in Figure 2 is under the active earth pressure state. Inspired by the experiments of Tsagareli [15] and Yang and Tang [19], an exponential expression of the curved slip surface was selected in this paper. The specific constraints of the formula are as follows: the slip surface passes through the bottom point and its diagonal vertex, that is, the points with coordinates of $(0,0)$ and $\left(L_{b}, H\right)$ in the given coordinate system shown in Figure 2.

The equation of the slip surface is specifically written as

$$
y=C\left[3.6 \cdot\left(\frac{\pi}{4}+\frac{\varphi}{2}+0.1\right)\right]^{x / C}-C,
$$

where $\varphi$ is the internal friction angle of the filling body; $C$ is a constant associated with the geometry parameters of the given filling body, which can be obtained by the abovementioned constraint conditions of the slip surface. It should be noted that an analytical expression for $C$ does not 


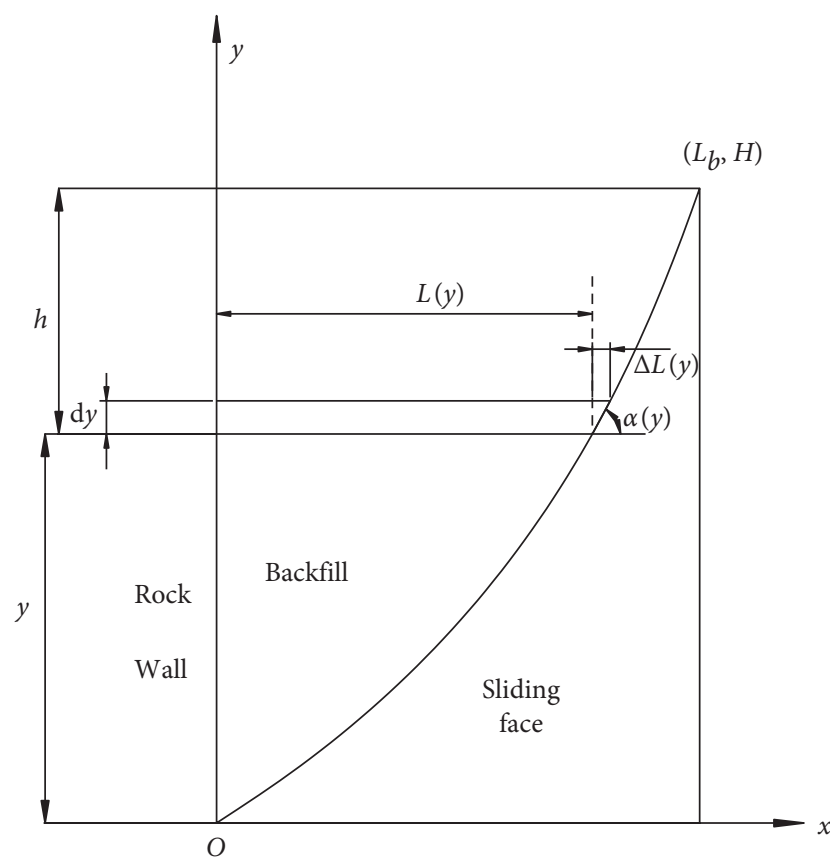

Figure 2: Side view of the backfill body.

exist for the complexity of the formula of the slip surface. Thus, it is necessary to substitute certain parameters of the given filling body to obtain a specific equation of slip surface.

As shown in Figure 3, comparing the slip surfaces obtained from the experimental data of Yang and Tang [19], the exponential slip surface proposed in this paper can satisfactorily describe the slip surface morphology of the vertical filling body under active earth pressure.

Then, the angle of the slip surface changing with height can be written as

$$
\begin{aligned}
\alpha(y)= & \tan ^{-1}\left[(1.8 \varphi+0.9 \pi+0.36)^{\ln (C+y) / \ln (1.8 \varphi+0.9 \pi+0.36)}\right. \\
& \cdot \ln (1.8 \varphi+0.9 \pi+0.36)] .
\end{aligned}
$$

The width of the sliding body varying with height can be deduced as

$$
L(y)=\frac{C \cdot \ln (C+y / C)}{\ln (1.8 \varphi+0.9 \pi+0.36)} .
$$

2.2. Estimation of Stress State. Handy [22] has long noticed the existence of friction at the wall-backfill interface and that the direction of the principal stress in the filling body will be deflected at a certain angle anyway. Then, the method of calculating the earth pressure with the minor principal stress trajectory was proposed. As shown in Figure 4, the minor principal stress trajectory method fully considers the disturbance of the wall-backfill friction to the stress distribution state of the filling body. So, it has been widely used in the calculation of earth pressure, especially the arcshaped minor principal stress trajectory $[18,23,24]$. For this reason, the horizontal slice method combined with arc-

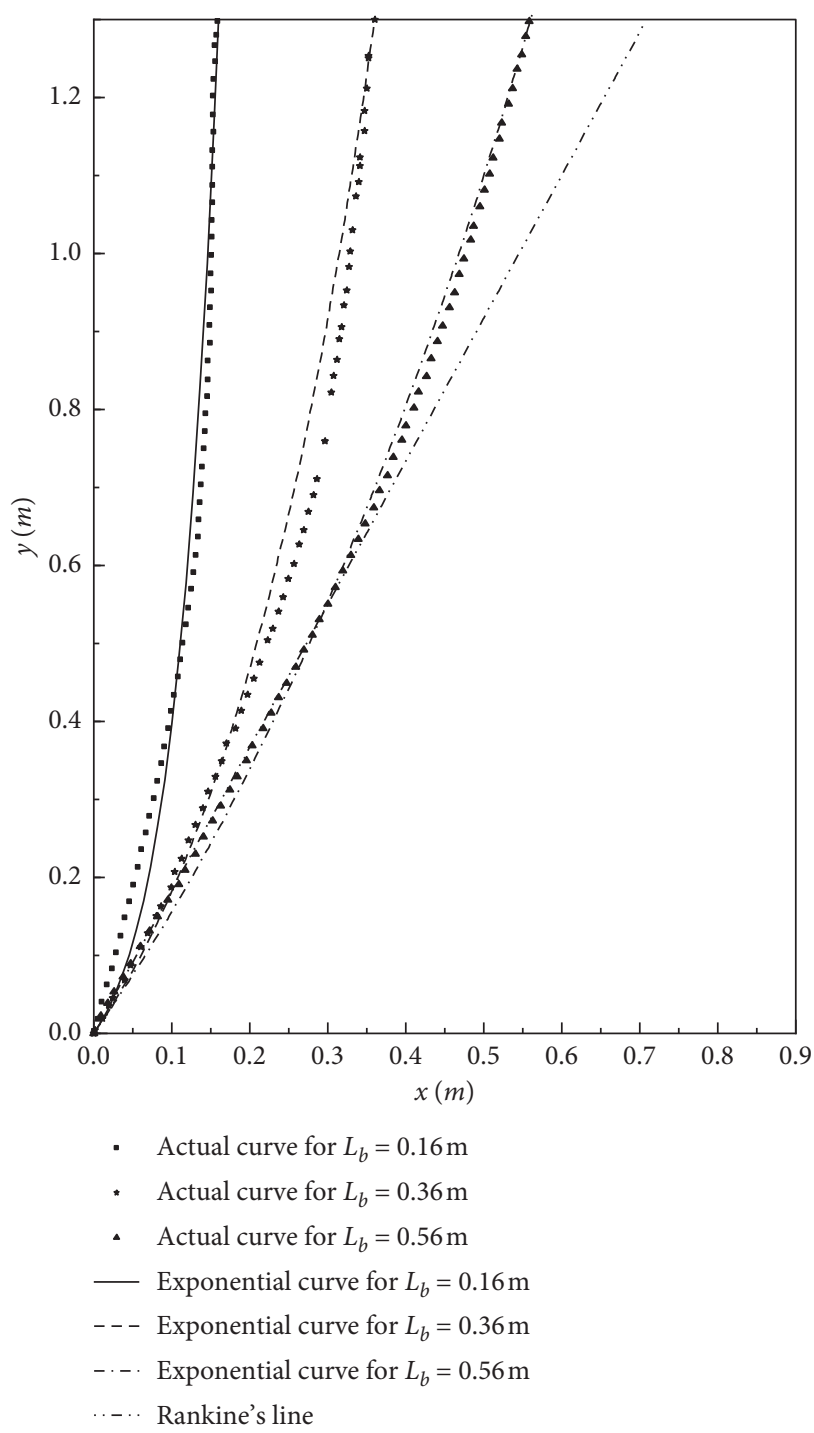

Figure 3: Comparison of the actual slip surface and proposed exponential slip surface.

shaped minor principal stress trajectory is also adopted in this paper for lateral pressure calculation, as shown in Figures 4 and 5 .

For a vertical rock face, the deflection angle of principal stress at the backfill-rock interface is [25]

$$
\theta_{w}=\frac{\pi}{2}-\frac{1}{2} \arcsin \left(\frac{\sin \delta}{\sin \varphi}\right)+\frac{\delta}{2} .
$$

As for the deflection angle of principal stress at the curved slip surface, the Mohr-stress circle at the slip surface drawn by the Mohr-Coulomb criterion shows that the angle between $\sigma_{n s}$ and $\sigma_{1}$ is always $\left(45^{\circ}+(\phi / 2)\right)$. Meanwhile, if the angle between the slip surface of the horizontal differential layer and the horizontal plane is notated as $\alpha$, that is, the angle between $\sigma_{h s}$ and $\sigma_{1}$ is $((\pi / 2)-\alpha)$, then the following expression of the deflection angle of principal stress at the slip surface can be obtained: 


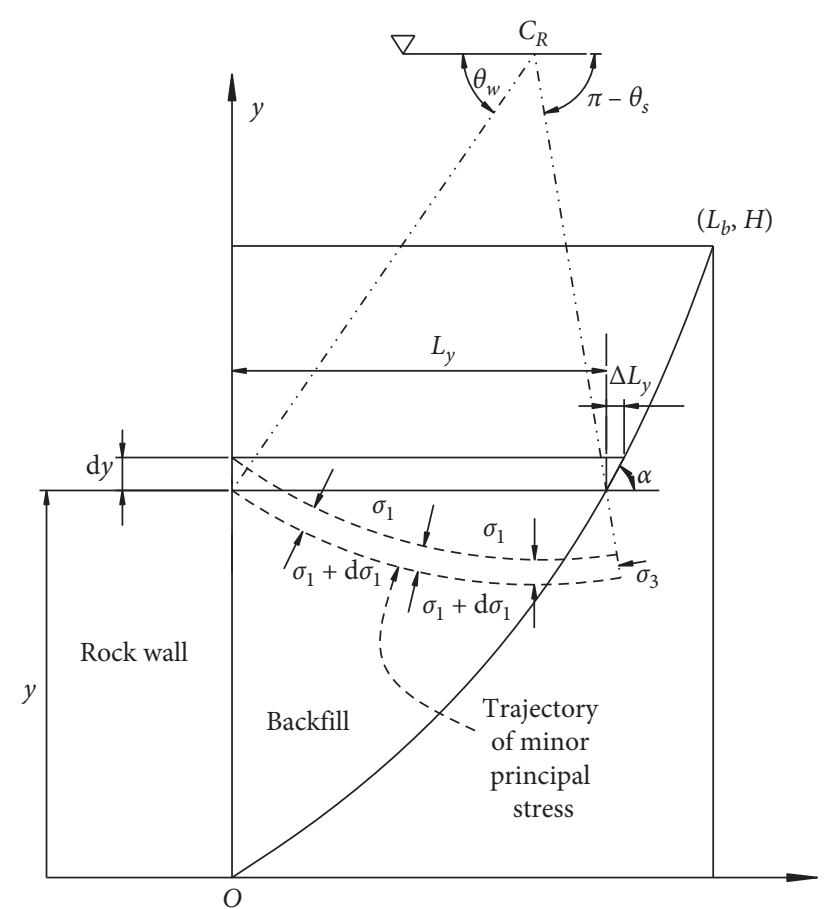

FIGURE 4: Schematic diagram of the minor principal stress trajectory.

$$
\theta_{s}=\pi-\left(\frac{\pi}{2}-\alpha\right)-\left(\frac{\pi}{4}+\frac{\varphi}{2}\right)=\frac{\pi}{4}+\alpha-\frac{\varphi}{2} .
$$

Therefore, for a curved slip surface, equations (6) and (7) can be obtained by using the arc-shaped minor principal stress trajectory hypothesis.

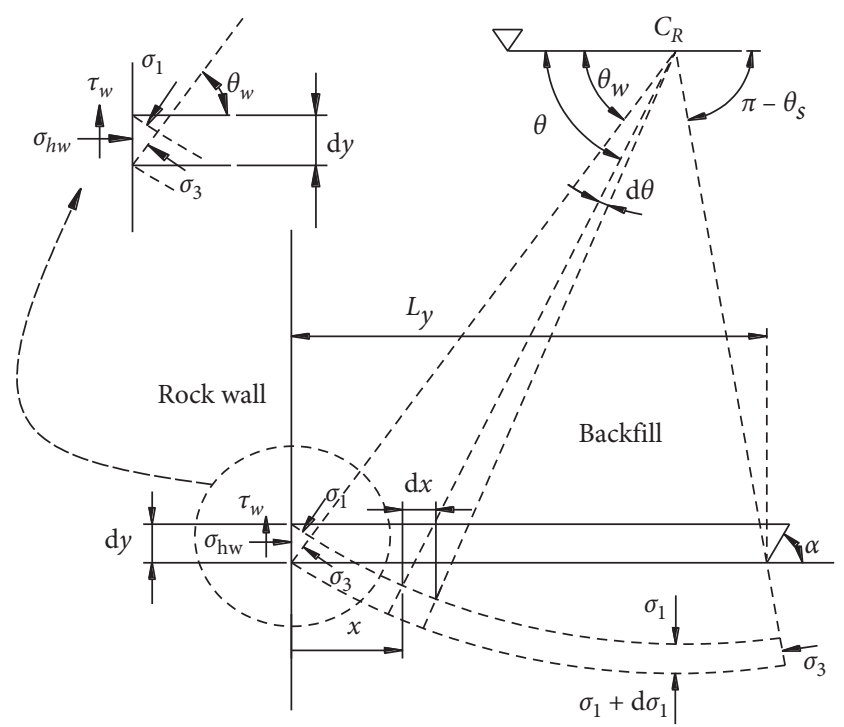

FIgURE 5: Horizontal slice method combined with arc-shaped minor principal stress trajectory.

$$
\begin{aligned}
\overline{\sigma_{y}}= & \frac{\int_{\theta_{w}}^{\theta_{s}} \sigma_{y} R \sin \theta \mathrm{d} \theta}{L_{y}}=\sigma_{1}\left[1-\frac{2 \sin \varphi}{3(1+\sin \varphi)}\right. \\
& \left.\cdot\left(\cos ^{2} \theta_{w}+\cos ^{2} \theta_{s}+\cos \theta_{s} \cdot \cos \theta_{w}\right)\right] . \\
\overline{\tau_{x y}}= & \frac{\int_{\theta_{w}}^{\theta_{s}} \tau_{x y} R \sin \theta \mathrm{d} \theta}{L_{y}}=\frac{2 \sigma_{1} \sin \varphi}{3(1+\sin \varphi)} \cdot \frac{\sin ^{3} \theta_{w}-\sin ^{3} \theta_{s}}{\cos \theta_{w}-\cos \theta_{s}} .
\end{aligned}
$$

Thus, the following equations are derived:

$$
\begin{aligned}
& K_{\mathrm{AVE}}=\frac{\sigma_{h w}}{\overline{\sigma_{y}}}=\frac{3\left(1+\sin \varphi \cdot \cos 2 \theta_{w}\right)}{3(1+\sin \varphi)-2 \sin \varphi \cdot\left(\cos ^{2} \theta_{w}+\cos ^{2} \theta_{s}+\cos \theta_{s} \cdot \cos \theta_{w}\right)}, \\
& K_{\tau}=\frac{\overline{\tau_{x y}}}{\overline{\sigma_{y}}}=\frac{2\left(\sin ^{3} \theta_{w}-\sin ^{3} \theta_{s}\right) \sin \varphi}{3(1+\sin \varphi)\left(\cos \theta_{w}-\cos \theta_{s}\right)-2\left(\cos ^{3} \theta_{w}-\cos ^{3} \theta_{s}\right) \sin \varphi}
\end{aligned}
$$

2.3. Establishment of Equilibrium Equation. Figure 6 is a schematic diagram of the force analysis of the differential strip of the filling body considering the horizontal shear stress. Assuming that the backfill-rock interface and the slip surface are both in the limit equilibrium state defined by the Mohr-Coulomb criterion, the following force analysis can be performed.

$T_{y}$ and $V_{y}$ are the shear force and vertical force in the given height $y$, respectively. $T_{w}$ and $N_{w}$ are the shear force and normal force acting on the backfill-rock interface in the given height $y$, respectively. And $N_{w}=\sigma_{h w} \cdot \mathrm{d} y ; T_{w}=\sigma_{h w}$. $\mathrm{d} y \cdot \tan \delta . T_{s}$ and $N_{s}$ are the shear force and normal force acting on the slip surface in the given height $y$, respectively.
And $T_{s}=\sigma_{n s} \cdot \tan \varphi \cdot \mathrm{d} y \cdot \csc \alpha ; N_{s}=\sigma_{n s} \cdot \mathrm{d} y \cdot \csc \alpha$. And the expressions for differential forces in Figure 6 can be listed as follows:

$$
\begin{aligned}
\mathrm{d} G & =\gamma \cdot \frac{\mathrm{d} y \cdot \mathrm{d} y}{2 \tan \alpha}+\gamma \cdot \mathrm{d} y \cdot L_{y}, \\
\mathrm{~d} T_{y} & =\mathrm{d} \overline{\tau_{x y}}\left(L_{y}+\mathrm{d} y \cot \alpha\right)+\overline{\tau_{x y}} \mathrm{~d} y \cdot \cot \alpha, \\
\mathrm{d} V_{y} & =\overline{\sigma_{y}} \mathrm{~d} y \cdot \cot \alpha+\mathrm{d} \overline{\sigma_{y}}\left(L_{y}+\mathrm{d} y \cot \alpha\right) .
\end{aligned}
$$

According to the force balance in horizontal direction, equation (10) can be obtained. 


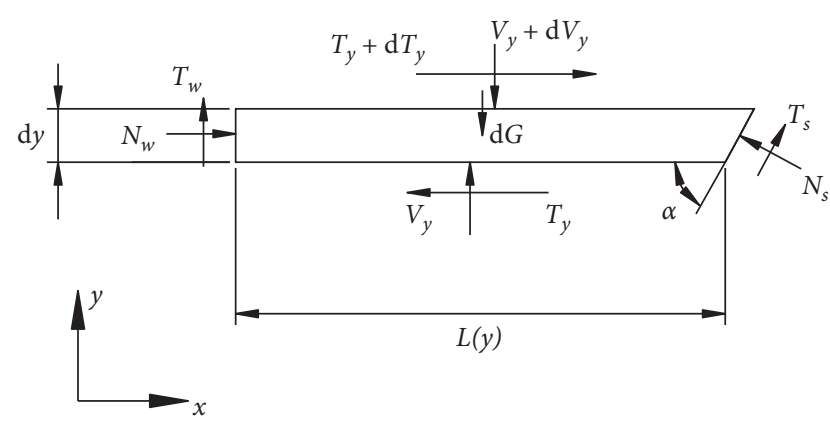

FIGURE 6: Force analysis of the differential horizontal backfill strip.

$$
\begin{aligned}
& \sigma_{h w} \cdot \mathrm{d} y+\sigma_{n s} \cdot \mathrm{d} y \cdot \cot \alpha \cdot \tan \varphi+\mathrm{d} \overline{\tau_{x y}}\left(L_{y}+\mathrm{d} y \cot \alpha\right) \\
& \quad+\overline{\tau_{x y}} \mathrm{~d} y \cdot \cot \alpha=\sigma_{n s} \cdot \mathrm{d} y .
\end{aligned}
$$

Dividing equation (10) by $\mathrm{d} y$ and eliminating the higherorder infinitesimal leads to the following equation:

$$
\frac{\mathrm{d} \overline{\tau_{x y}}}{\mathrm{~d} y}+\frac{\sigma_{h w}+\sigma_{n s} \cdot \cot \alpha \cdot \tan \varphi+\overline{\tau_{x y}} \cdot \cot \alpha}{L_{y}}=\frac{\sigma_{n s}}{L_{y}} .
$$

Similarly, the equilibrium equation in vertical direction can be obtained as

$$
\frac{\mathrm{d} \overline{\sigma_{y}}}{\mathrm{~d} y}+\frac{\overline{\sigma_{y}} \cdot \cot \alpha}{L_{y}}=-\gamma+\frac{\sigma_{h w} \tan \delta+\sigma_{n s} \cdot(\tan \varphi+\cot \alpha)}{L_{y}} \text {. }
$$

After introducing $\sigma_{h w}=K_{\mathrm{AVE}} \cdot \overline{\sigma_{y}}$ and $\overline{\tau_{x y}}=K_{\tau} \cdot \overline{\sigma_{y}}$, equation (10) becomes

$$
\frac{\mathrm{d} \overline{\tau_{x y}}}{\mathrm{~d} y}+\frac{\sigma_{h w}+\sigma_{n s} \cdot \cot \alpha \cdot \tan \varphi+K_{\tau} \overline{\sigma_{y}} \cdot \cot \alpha}{L_{y}}=\frac{\sigma_{n s}}{L_{y}} .
$$

By $\mathrm{d} \overline{\tau_{x y}}=\mathrm{d} K_{\tau} \cdot \overline{\sigma_{y}}+K_{\tau} \cdot \mathrm{d} \overline{\sigma_{y}}$, equation (13) is further written as

$$
\begin{aligned}
& \frac{\mathrm{d} K_{\tau}}{\mathrm{d} y} \cdot \overline{\sigma_{y}}+\frac{\mathrm{d} \overline{\sigma_{y}}}{\mathrm{~d} y} \cdot K_{\tau} \\
& \quad+\frac{K_{\mathrm{AVE}} \overline{\sigma_{y}}+\sigma_{n s} \cdot \cot \alpha \cdot \tan \varphi+K_{\tau} \overline{\sigma_{y}} \cdot \cot \alpha}{L_{y}}=\frac{\sigma_{n s}}{L_{y}} .
\end{aligned}
$$

Similarly, the vertical balance equation can be rewritten as

$\frac{\mathrm{d} \overline{\sigma_{y}}}{\mathrm{~d} y}+\frac{\overline{\sigma_{y}} \cdot \cot \alpha}{L_{y}}=-\gamma+\frac{K_{\mathrm{AVE}} \tan \delta \cdot \overline{\sigma_{y}}+\sigma_{n s} \cdot(\tan \varphi+\cot \alpha)}{L_{y}}$.

Then, the ordinary differential equation for average vertical stress in the backfill can be obtained as equation (16) by combining equations (14) and (15).

$$
\frac{\mathrm{d} \overline{\sigma_{y}}}{\mathrm{~d} y}\left[1-K_{\tau} \cdot \cot (\alpha-\varphi)\right]+\overline{\sigma_{y}} \cdot\left[\frac{\cot \alpha-K_{\mathrm{AVE}} \tan \delta-\cot (\alpha-\varphi) K_{\mathrm{AVE}}-\cot (\alpha-\varphi) K_{\tau} \cdot \cot \alpha}{L_{y}}-\frac{\mathrm{d} K_{\tau}}{\mathrm{d} y} \cot (\alpha-\varphi)\right]+\gamma=0
$$

The use of circular minor stress trajectory may also have other substitutes because the method of minor stress trajectory is just a semi-analytical method. Furthermore, the established ordinary differential equation cannot be solved analytically because several transcendental functions are within this function.

\section{Strength Design of the Cemented Backfill}

3.1. Calculation of Lateral Pressure Stress. The specific expressions of $L(y)$ and $\alpha(y)$ in equation (16) are determined by the formula of slip surface; the expressions of $K_{\mathrm{AVE}}(y)$ and $K_{\tau}(y)$ are determined by the stress distribution described by the arc-shaped minor principal stress trajectory. The distribution of average vertical stress with height can be obtained by solving equation (16) numerically. Then, the solution can be used to obtain the distribution of the lateral pressure.
3.2. Analysis on the Limit Equilibrium Model. As shown in Figure 1, the weight of the sliding body is

$$
W_{n}=W \cdot H^{*}\left(\gamma L_{b}-2 C_{b}\right)-2 P \tan \delta,
$$

where $C_{b}$ is the cohesion of the backfill-rock interface; $H^{*}=H-W \tan \beta / 2 ; P$ is the lateral pressure force acting on the filling body; and the sliding angle $\beta$ is generally taken as $\beta=45^{\circ}+\varphi / 2$, according to Mitchell's experiments [20].

The safety factor of the sliding body is then calculated as

$$
\mathrm{FS}=\frac{\tan \varphi}{\tan \beta}+\frac{2 c L_{b}}{\left(H^{*} \gamma L_{b}-2 P \tan \delta-2 H^{*} C_{b}\right) \sin 2 \beta},
$$

where $c$ is the apparent cohesion along the slip surface. If it is considered that $\mathrm{FS}=1, C_{b}=c$, the cohesion $c$ required for any given internal friction angle $\varphi$ is

$$
c=\frac{\gamma L H-0.5 \cdot \gamma L W \tan \beta-2 P \tan \delta}{2 H-W \tan \beta-2 L(\tan \beta \sec \varphi / \tan \varphi-\tan \beta)} .
$$


From the abovementioned expression, it can be seen that when other parameters are given and fixed, the larger the $P$, the smaller the required cohesion. To ensure a conservative design, it is necessary to find a $P$ value that is accurate enough but little less than the actual value to achieve a safe design.

3.3. Process for Designing the Required Strength. As mentioned above, the calculation of the lateral pressure in the case of curved siding face is specific to the parameters of given filling body, that is, the geometry of filling body and the friction angle of the backfill-rock interface and the internal friction angle of the filling body. These data can be directly selected from typical data, such as studies of Liu et al. [21], Chen et al. [26], Falaknaz et al. [27], Jahanbakhshzadeh et al. [28], and Yang et al. [29]. And it is recommended to obtain approximate parameters in advance according to the results of the proportioning test in a laboratory. Also, one can select parameters within a certain range and then take the mean value of the lateral pressure force. If a conservative calculation is needed, it is suggested to take smaller values of $\varphi$ and $\delta$.

If the abovementioned lateral pressure calculation method is used to obtain a dimensionless lateral pressure distribution of $g(y)=\sigma_{y}(y) K_{\mathrm{AVE}}(y) / \gamma H$, the lateral pressure force is calculated as

$$
P=\gamma H \cdot \int_{0}^{W} \int_{x \cdot \tan \beta}^{H} g(y) \mathrm{d} y \mathrm{~d} x .
$$

The abovementioned integrals also need to be numerically integrated, and the lateral pressure force $P$ is obtained and then substituted into equation (19) to obtain the required strength design parameters.

\section{Verification and Discussion of the Proposed Method}

In order to verify the reliability of the new calculation method for lateral pressure and the required strength of the backfill, the calculated lateral pressure and the designed strength of the filling body were verified. Lateral pressure on sides of the backfill was calculated and then submitted into equation (19) to evaluate the required cohesion. After that, the calculated cohesions were compared with those of previous studies and then used as cohesion parameters in FLAC3D models to evaluate the stability of the backfill.

4.1. Computation of Lateral Pressure. The solid data points in Figure 7 are the data from [29] and also [19]. The hollow data points are calculated using the proposed method. It can be seen from the comparison that the proposed method can predict the lateral pressure well. When the buried depth is relatively large, the calculated results are kind of different from the measured data, which can be viewed from the following perspectives.

Firstly, Wu et al. [30] pointed out that the experimental data given by Yang et al. [29] is consistent with similar experimental data in the shallow part, but there is a problem

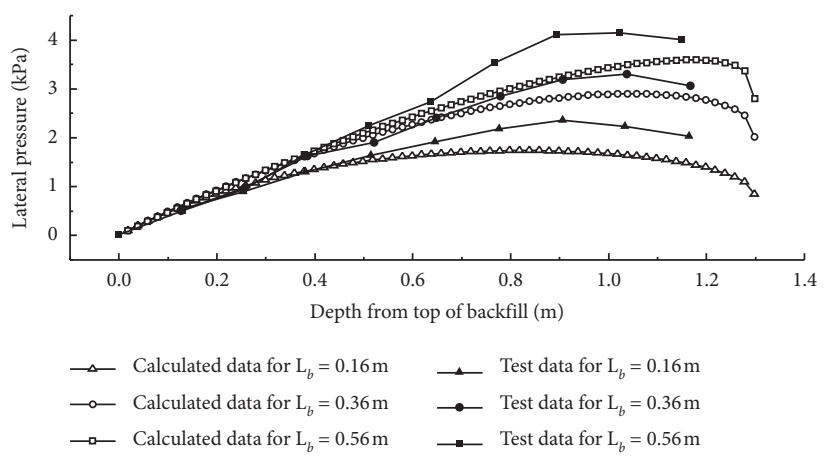

Figure 7: Measured and calculated lateral pressure versus depth.

of larger earth pressure when the depth is large, which is not consistent with similar experimental data. Then, Yang [31] replied that this may be due to the fact that the experimental conditions are not fully guaranteed according to theoretical analysis, including the failure to ensure that the wall is completely in translational move and the fact that the friction of wall-backfill is complicatedly distributed along the wall. Thus, the actual experiment does not completely correspond to the experimental design that is theoretically hypothesized and desired. Secondly, as mentioned above, the purpose of this paper is to find a pressure that is close to the actual lateral pressure but less than the actual side pressure. This will not overestimate the lateral friction and antisliding force of the filling body and can guarantee a safe design as well as certain excess safety factor for dynamic disturbance.

Figures 8 and 9 depict the results of lateral pressure force and lateral friction calculated with the proposed method under the condition that $\delta=\varphi$, respectively.

It is showed that the lateral pressure increases at an increasing rate with the increase in aspect ratio $\left(H / L_{b}\right)$, and the smaller the friction angle, the larger the side pressure.

The reason why a smaller friction angle will lead to a larger side pressure under the same geometric conditions is that the friction angles of the filling body and the backfillrock interface is synchronously reduced, and when a lower value is taken, the backfill is closer to the hydrostatic pressure state, and thus the surrounding rock is subjected to the maximum pressure in the hydrostatic pressure state. Although the lateral pressure $P$ contributing to frictional resistance becomes larger under smaller values of $\varphi$ and $\delta$, the overall instability resistance decreases. This can be seen from the increase in the cohesion required for the backfill in the following section, which fully demonstrates that the stability of the backfill is not simply linear. If the $\delta$ used in the calculation of lateral pressure is larger than $\varphi$, a complex value with an imaginary part of $P$ may occur, which means that $\delta$ should be no more than $\varphi$ in the physical sense. Similarly, if the friction angle used to calculate the minimal cohesion is greater than the friction angle used to calculate the side pressure, then the resulting cohesion will also be wrong and there may exist a negative value, which indicates that the friction angle has an important influence on the stability of the filling body and need to be identified carefully. 


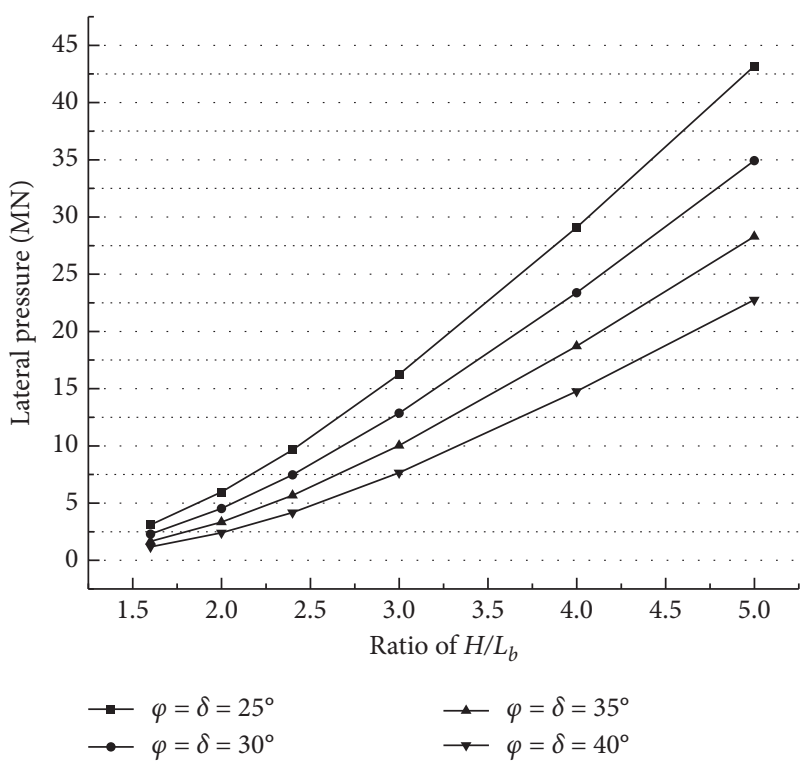

Figure 8: Calculated lateral pressure force versus aspect ratio.

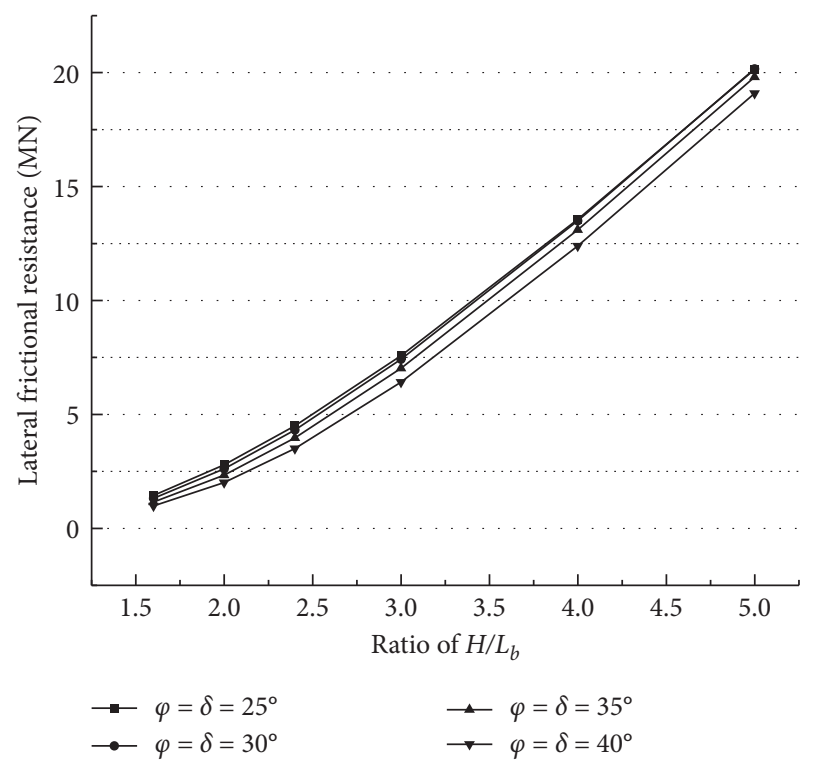

FIGURE 9: Calculated lateral resistance force versus aspect ratio.

4.2. Computation of the Required Cohesion. The calculated results of the required cohesion under the condition that $\delta=\varphi, \mathrm{FS}=1$ and $f_{b}=1$ are shown in Figure 10 .

The minimal cohesion increases with the increase in aspect ratio. Under the same geometric parameters, the larger the friction angle is, the smaller the required cohesion is. Similarly, under the same cohesion, a larger friction angle would allow for a larger aspect ratio. After the aspect ratio exceeds a certain threshold, the cohesion required seems to decrease slightly. However, the abovementioned results are based on the fact that the damage of the backfill is close to the wedge-shaped failure; for the filling body with a larger aspect ratio, whether the failure mode is still the wedge sliding or it is toppling over or of some other forms, need to be identified

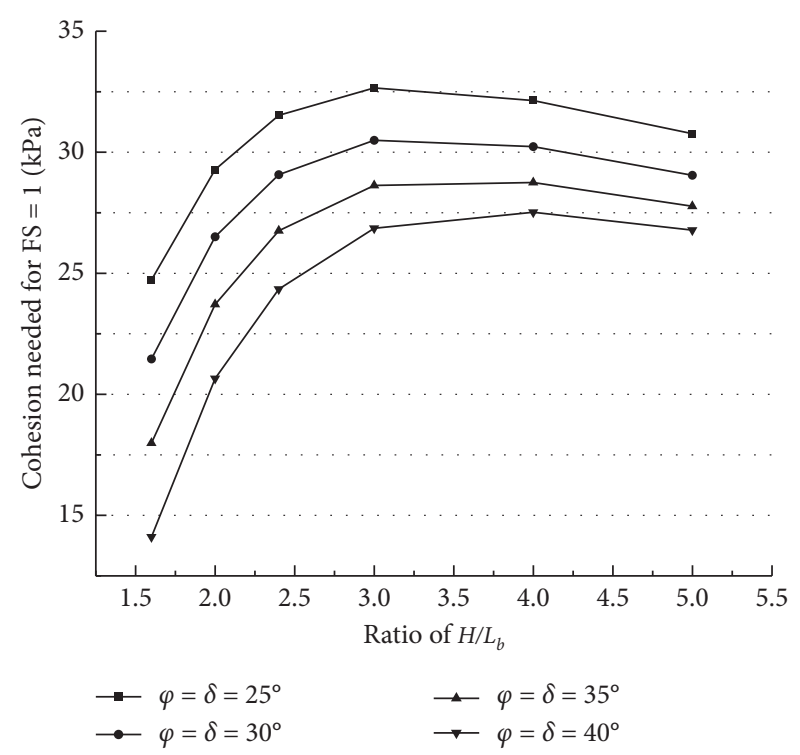

FIgURE 10: Calculated minimal cohesion versus aspect ratio.

with the experiment, and then it is decided whether to use the calculated cohesion value or not.

4.3. Comparison of the Required Cohesion. In the case that the safety factor is 1 and the cohesion and friction angle of the rock-backfill interface are equal to those of the backfill, the calculated cohesion were compared with results from previous methods by Mitchell [20], Li and Aubertin [32], Li [9], and Li and Aubertin [33]. The comparison results are shown in Figure 11.

The curves show that the cohesions calculated with the same given parameters are lower than the results given by Mitchell et al. [20], Li and Aubertin [32], and Li [9]. And when the aspect ratio is less than 4 , the calculated results are larger than those of $\mathrm{Li}$ and Aubertin, [33], but when the aspect ratio is greater than 4, the calculated results are slightly smaller than those given by Li and Aubertin [33]. These comparisons show that the design of the backfill strength proposed in this paper is effective and slightly conservative, but it has been greatly improved compared with the traditional method.

4.4. Verification with Numerical Modeling. The effective stress in the cemented backfill is evolutive [6, 34], which means that the strength parameters of the cemented backfill will develop from zero to a peak and then decline gradually. Furthermore, the stress boundary condition of the backfill is changing too [7]. These dynamic changes may come from many factors, such as disturbance from blasting or other dynamic loads, multiphysical consolidation process, and the attenuation effect from corrosive underground water and sulphate. However, the research on the influence of these factors is still ongoing $[3,4,35]$ and cannot be quantified easily in laboratory modelling and numerical modelling. And to assess the validation of the proposed method, numerical modelling was proved to be an effective way 


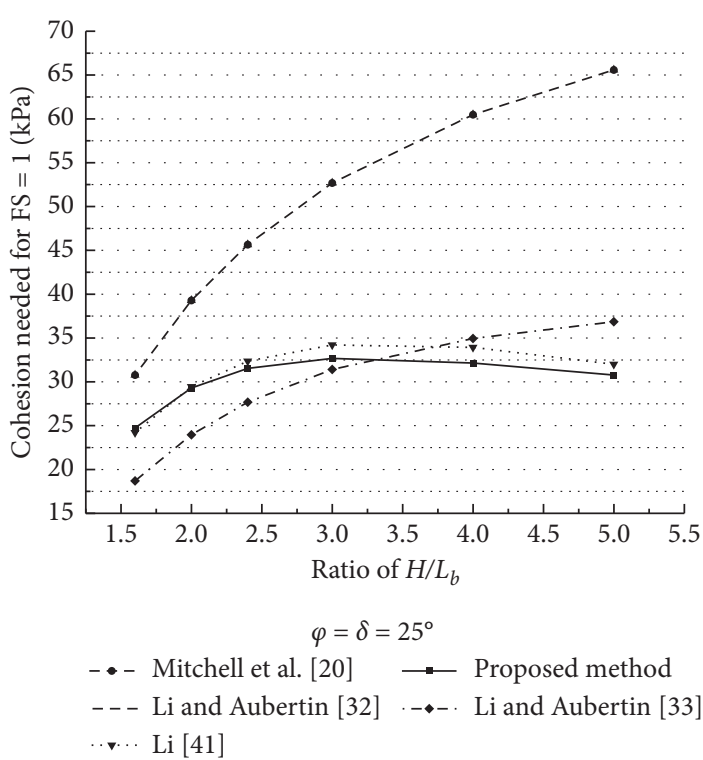

(a)

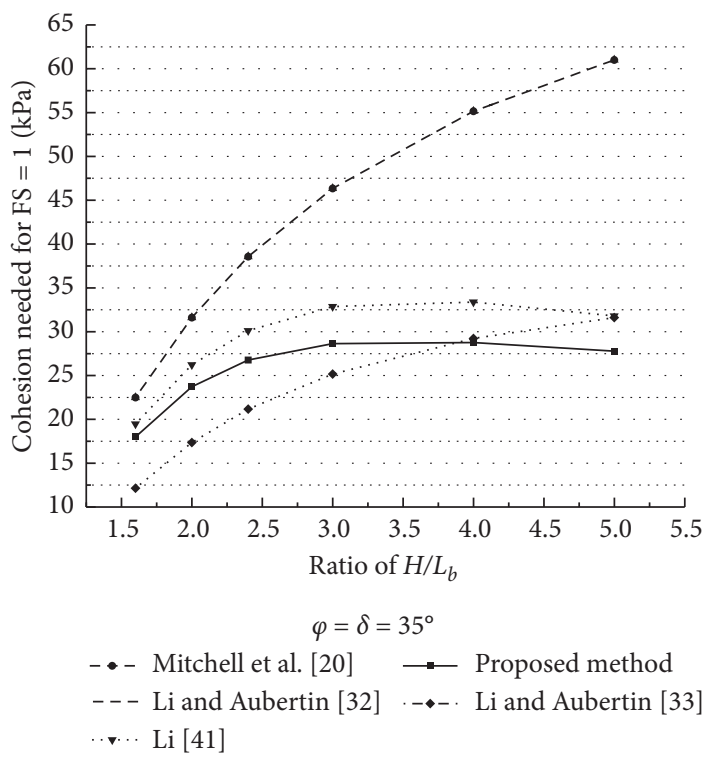

(c)

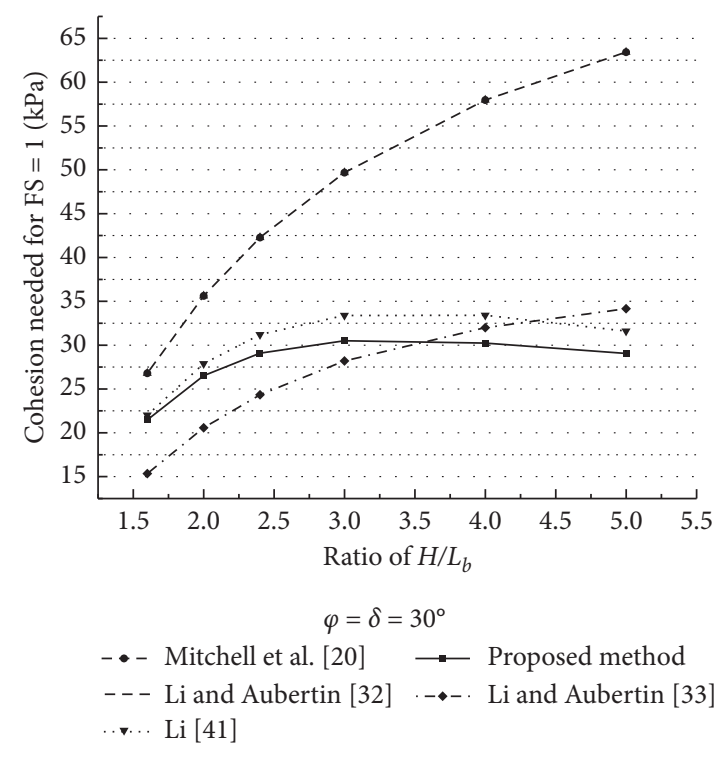

(b)

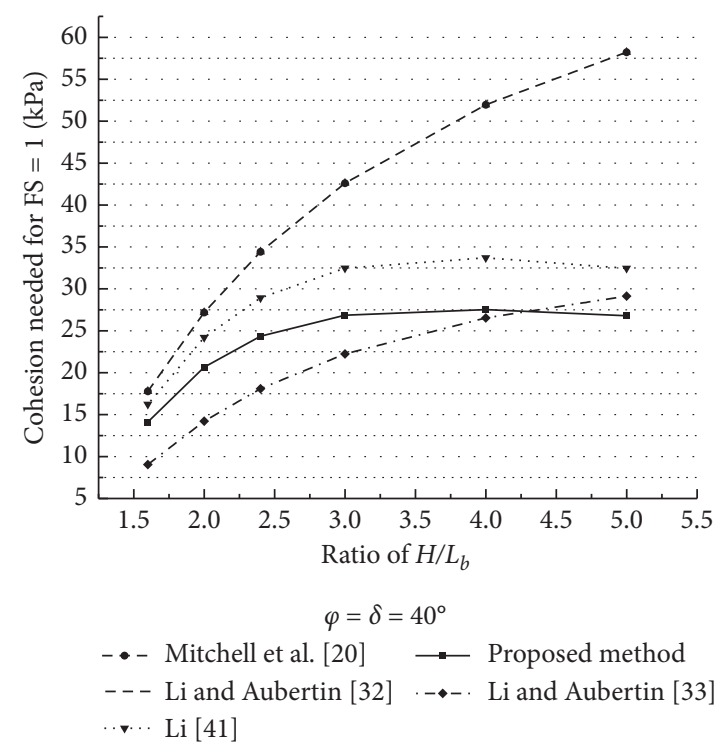

(d)

FIGURE 11: Comparison of the proposed method and previous methods: (a) $\varphi=\delta=25^{\circ}$; (b) $\varphi=\delta=30^{\circ}$; (c) $\varphi=\delta=35^{\circ}$; and (d) $\varphi=\delta=40^{\circ}$.

$[2,11,12,21,33,36-41]$. To assess the stability of the backfill using 3D numerical simulations was proved to be effective [2, 28-32]. Geometric and mechanical parameters used in numerical modeling were taken as typical values from previous studies $[7,8,11,12,20,36,38]$. The width and length of the backfill are fixed to $10 \mathrm{~m}$; the heights of the backfill were taken as $16 \mathrm{~m}, 20 \mathrm{~m}, 24 \mathrm{~m}, 30 \mathrm{~m}, 40 \mathrm{~m}$, and $50 \mathrm{~m}$, a total of 6 different values. The size of the whole numerical model is varying from $330 \mathrm{~m} \times 350 \mathrm{~m} \times 400 \mathrm{~m}$ to $330 \mathrm{~m} \times 350 \mathrm{~m} \times 500 \mathrm{~m}$ according to the height of the backfill to avoid the boundary effect. Four different friction angle values of $25^{\circ}, 30^{\circ}, 35^{\circ}$, and $40^{\circ}$ were used for each aspect ratio. Other parameters of the filling body are unit weight $\gamma=18 \mathrm{kN} / \mathrm{m}^{3}$, Young's modulus $E=300 \mathrm{MPa}$, and Poisson's ratio $\nu=0.3$. Mechanical parameters of rock were taken as typical values from previous studies $[7,8,11,12,36,38]$ : unit weight $\gamma=27 \mathrm{kN} / \mathrm{m}^{3}$, Young's modulus $E=30 \mathrm{GPa}$, and Poisson's ratio $v=0.25$. The four vertical boundaries of meshes were constricted using roller support. The bottom of meshes was fixed, and the top of the meshes was set as free face.

Some representative results of these 24 cases were selected and shown in Figures 12 and 13. Figure 12 depicts the contours of displacement to reveal the potential slip surface. Figure 13 illustrates the contours of strength to stress ratio to assess the safety factor of the backfill.

White-colored parts in Figure 12 stand for the backfill with relatively large displacement towards the void space. From its outline, the general shape of the sliding body may be obtained. 

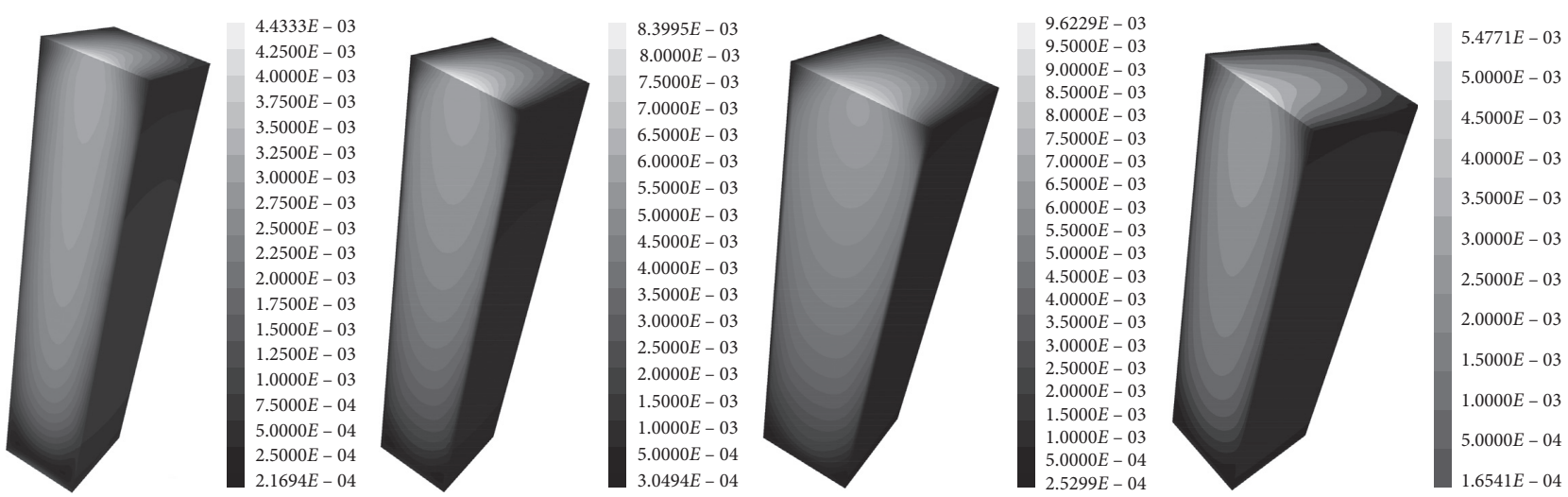

Figure 12: Typical contours of displacement of the exposed backfill. (a) $H=50 \mathrm{~m}, \varphi=\delta=40^{\circ}$ (b) $H=50 \mathrm{~m}, \varphi=\delta=25^{\circ}$, (c) $H=40 \mathrm{~m}$, $\varphi=\delta=25^{\circ}$, and (d) $H=50 \mathrm{~m}, \varphi=\delta=40^{\circ}$.
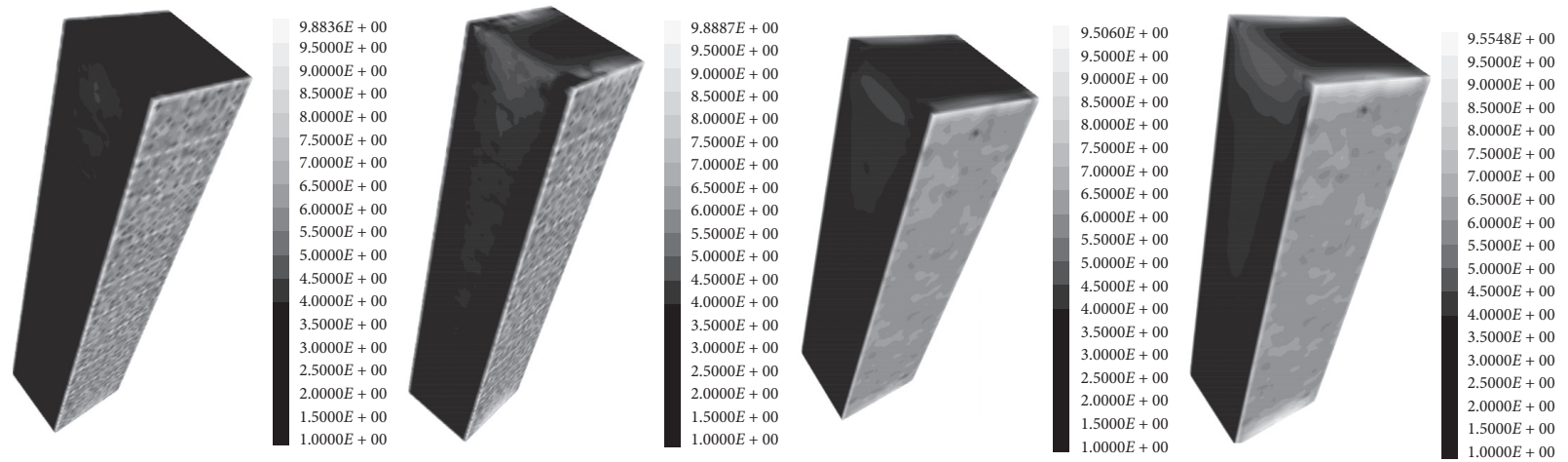

Figure 13: Typical contours of strength-stress ratio of the exposed backfill. (a) $H=50 \mathrm{~m}, \varphi=\delta=25^{\circ}$, (b) $H=50 \mathrm{~m}, \varphi=\delta=40^{\circ}$, (c) $H=40 \mathrm{~m}$, $\varphi=\delta=25^{\circ}$, and (d) $H=40 \mathrm{~m}, \varphi=\delta=40^{\circ}$.

Figure 12 shows that the shape of potential sliding body is close to the wedge used in limit equilibrium analysis, which is similar to results of physical experiments [20]. In Figure 13, zones with a color closer to white indicate a larger safety factor. And if matched with the analytical method strictly, the safety factor of the backfill should be one. Figure 13 shows that the backfills are in the stable state in the cases calculated since the minimum of strength-stress ratio is one, a totally black region. In most regions of the backfill, the equivalent safety factor (strength-stress ratio) is greater than 1 but less than 3. The safety factor of a small part of the backfill is relatively large, and the maximum value can reach about 10 . This shows that the safety factor of the major area is enough, but the margin is not large, which effectively reduces the cost of the cement on the basis of ensuring safety.

However, the stress state and boundary condition of the backfill are evolutive. And such evolution is resulted from many factors, including the development of the hydration process, the evolution of pore water pressure, dynamic loading on the backfill, and the evolutive boundary conditions of the backfill (flow of groundwater, attenuation of cohesion and friction between rock-backfill interface, and changing temperature). Furthermore, the strength parameters of the backfill can be weakened by corrosion of hydration products under the influence of corrosive underground water or sulphate. But, the quantification of these influences still needs further study. So, a safety factor usually larger than 1.5 was adopted in practice, which means the adopted strength data will not be in direct correspondence with the designed parameters. So, for a more precise and economical design, a more complicated analysis (taking time factor, dynamic factor, and multiphysical coupling effects into consideration) is about to be developed.

\section{Conclusions}

This paper focuses on the calculation method intended for the lateral pressure and strength design of the backfilling body with high aspect ratio (the ratio of the height of free face to the length of free face $\left.>\tan \left(45^{\circ}+\varphi / 2\right)\right)$ for mines. The core objective of the present study is to develop a strength design method for cemented backfills with high aspect ratios.

A formulation of the slip surface and a lateral pressure calculation method based on the curved slip surface was proposed. The calculation method of the lateral pressure of the filling body with high aspect ratio was obtained. The lateral pressure can be calculated from given parameters of the filling body, including the height and length of the backfill, the friction angles of the backfill, and the backfillrock interface. Then, the method based on Mitchell's threedimensional limit equilibrium model was used to calculate the required strength of the cemented backfill. The calculated results were compared with previous studies and validated 
with the numerical models. The results showed good consistency for the backfills with high aspect ratios.

\section{Abbreviations}

C: $\quad$ Constant used in the exponential slip surface

C: $\quad$ Cohesion of the backfill

$C_{b}$ : Cohesion of the backfill-rock interface

G: $\quad$ Gravity

$H$ : $\quad$ Total height of the backfill

$h$ : $\quad$ Buried depth from the top of the backfill

$K_{\mathrm{AVE}}(y)$ : Ratio of $\sigma_{h w}$ to $\overline{\sigma_{y}}$

$K_{\tau}(y): \quad$ Ratio of $\frac{\tau_{x y}}{\text { to }} \overline{\sigma_{y}}$

$L_{b}$ : $\quad$ Length of the filling body

$L_{y}$ : $\quad L(y)=$ width of sliding body at a given height $y$

$N_{w}$ : Normal stress at the rock-backfill interface

$N_{s}$ : $\quad$ Normal stress at the slip surface

$P$ : $\quad$ Lateral pressure force of the backfill

$R: \quad$ Radius of circle of minor principal stress

$T_{w}$ : Tangential stress at the rock-backfill interface

$T_{s}$ : $\quad$ Tangential stress at the slip surface

$V_{y}: \quad$ Vertical force on the horizontal backfill strip at a given height of $y$

$W$ : $\quad$ Width of the backfill

$W_{n}$ : $\quad$ Gravity of the sliding body

$y: \quad$ Height of the horizontal backfill strip

$\alpha: \quad$ Inclination of the horizontal backfill strip

$\beta$ : $\quad$ Sliding angle when the backfill is about to fail

$\gamma$ : $\quad$ Unit weight of the backfill

$\delta: \quad$ Friction angle of the rock-backfill interface

$\theta_{s}$ : $\quad$ Rotation angle of major principal stress at the slip surface

$\theta_{w}$ : $\quad$ Rotation angle of major principal stress at the rock-backfill interface

$\sigma_{h s}: \quad$ Horizontal stress at the slip surface

$\sigma_{h w}: \quad$ Horizontal stress at the rock-backfill interface

$\sigma_{n s}: \quad \quad \quad$ Normal stress at the slip surface

$\sigma_{n w}: \quad \quad \quad$ Normal stress at the rock-backfill interface

$\frac{n w}{\sigma_{y}}: \quad$ Average vertical stress on the horizontal backfill at a given height of $y$

$\sigma_{1}: \quad$ Major principal stress

$\sigma_{3}: \quad$ Minor principal stress

$\overline{\tau_{x y}}$ : Average horizontal shear stress on the backfill layer at a given height of $y$

$\varphi$ : $\quad$ Internal friction angle of the backfill.

\section{Data Availability}

The data will be available once required.

\section{Conflicts of Interest}

The authors declare that there are no conflicts of interest regarding the publication of this paper.

\section{Acknowledgments}

This research was funded by the National Key R\&D Program of China, grant no. 2017YFC0602903 and the State Key
Program of the National Natural Science Foundation of China, grant no. 51834001.

\section{References}

[1] N. Sivakugan, R. M. Rankine, K. J. Rankine, and K. S. Rankine, "Geotechnical considerations in mine backfilling in Australia," Journal of Cleaner Production, vol. 14, no. 12-13, pp. 1168-1175, 2006.

[2] T. Belem and M. Benzaazoua, "Design and application of underground mine paste backfill technology," Geotechnical and Geological Engineering, vol. 26, no. 2, pp. 147-174, 2008.

[3] L. Cui and M. Fall, "A coupled thermo-hydro-mechanicalchemical model for underground cemented tailings backfill," Tunnelling and Underground Space Technology, vol. 50, pp. 396-414, 2015.

[4] L. Cui and M. Fall, "Multiphysics model for consolidation behavior of cemented paste backfill," International Journal of Geomechanics, vol. 17, no. 3, Article ID 04016077, 2016.

[5] E. Yilmaz, T. Belem, and M. Benzaazoua, "Effects of curing and stress conditions on hydromechanical, geotechnical and geochemical properties of cemented paste backfill," Engineering Geology, vol. 168, pp. 23-37, 2014.

[6] M. Helinski, M. Fahey, and A. Fourie, "Behavior of cemented paste backfill in two mine stopes: measurements and modeling," Journal of Geotechnical and Geoenvironmental Engineering, vol. 137, no. 2, pp. 171-182, 2010.

[7] B. D. Thompson, W. F. Bawden, and M. W. Grabinsky, "In situ measurements of cemented paste backfill at the Cayeli mine," Canadian Geotechnical Journal, vol. 49, no. 7, pp. 755-772, 2012.

[8] M. Fall and O. Nasir, "Mechanical behaviour of the interface between cemented tailings backfill and retaining structures under shear loads," Geotechnical and Geological Engineering, vol. 28, no. 6, pp. 779-790, 2010.

[9] L. Li, "Generalized solution for mining backfill design," International Journal of Geomechanics, vol. 14, no. 3, p. 04014006, 2013.

[10] M. Helinski, Mechanics of Mine Backfill, University of Western Australia, Perth, Australia, 2007.

[11] A. Jahanbakhshzadeh, M. Aubertin, and L. Li, "Three-dimensional stress state in inclined backfilled stopes obtained from numerical simulations and new closed-form solution," Canadian Geotechnical Journal, vol. 55, no. 6, pp. 810-828, 2017.

[12] G.-s. Liu, L. Li, X.-c. Yang, and L.-j. Guo, "Numerical analysis of stress distribution in backfilled stopes considering interfaces between the backfill and rock walls," International Journal of Geomechanics, vol. 17, no. 2, Article ID 06016014, 2016.

[13] C. H. Ting, S. K. Shukla, and N. Sivakugan, "Arching in soils applied to inclined mine stopes[J]," International Journal of Geomechanics, vol. 11, no. 1, pp. 29-35, 2010.

[14] M. A. Sobhi and L. Li, "Numerical investigation of earth pressure coefficient along central line of backfilled stopes," Canadian Geotechnical Journal, vol. 54, no. 1, pp. 138-145, 2016.

[15] Z. V. Tsagareli, "Experimental investigation of the pressure of a loose medium on retaining walls with a vertical back face and horizontal backfill surface," Soil Mechanics and Foundation Engineering, vol. 2, no. 4, pp. 197-200, 1965.

[16] Y.S. Fang and I. Ishibashi, "Static earth pressures with various wall movements," Journal of Geotechnical Engineering, vol. 112, no. 3, pp. 317-333, 1986. 
[17] S. Goel and N. R. Patra, "Effect of arching on active earth pressure for rigid retaining walls considering translation mode," International Journal of Geomechanics, vol. 8, no. 2, pp. 123-133, 2008.

[18] M. H. Khosravi, T. Pipatpongsa, and J. Takemura, "Theoretical analysis of earth pressure against rigid retaining walls under translation mode," Soils and Foundations, vol. 56, no. 4, pp. 664-675, 2016.

[19] M. Yang and X. Tang, "Rigid retaining walls with narrow cohesionless backfills under various wall movement modes," International Journal of Geomechanics, vol. 17, no. 11, Article ID 04017098, 2017.

[20] R. J. Mitchell and B. C. Wong, "Behaviour of cemented tailings sands," Canadian Geotechnical Journal, vol. 19, no. 3, pp. 289-295, 1982.

[21] G. Liu, L. Li, X. Yang, and L. Guo, "Stability analyses of vertically exposed cemented backfill: a revisit to Mitchell's physical model tests," International Journal of Mining Science and Technology, vol. 26, no. 6, pp. 1135-1144, 2016.

[22] R. L. Handy, "The arch in soil arching," Journal of Geotechnical Engineering, vol. 111, no. 3, pp. 302-318, 1985.

[23] K. H. Paik and R. Salgado, "Estimation of active earth pressure against rigid retaining walls considering arching effects," Géotechnique, vol. 53, no. 7, pp. 643-653, 2003.

[24] M. H. Khosravi, T. Pipatpongsa, and J. Takemura, "Experimental analysis of earth pressure against rigid retaining walls under translation mode," Géotechnique, vol. 63, no. 12, pp. 1020-1028, 2013.

[25] P.-p. Rao, Q.-s. Chen, Y.-t. Zhou, S. Nimbalkar, and G. Chiaro, "Determination of active earth pressure on rigid retaining wall considering arching effect in cohesive backfill soil," International Journal of Geomechanics, vol. 16, no. 3, Article ID 04015082, 2015.

[26] Q.-s. Chen, Q.-1. Zhang, A. Fourie, X. Chen, and C.-c. Qi, "Experimental investigation on the strength characteristics of cement paste backfill in a similar stope model and its mechanism," Construction and Building Materials, vol. 154, pp. 34-43, 2017.

[27] N. Falaknaz, M. Aubertin, and L. Li, "Numerical analyses of the stress state in two neighboring stopes excavated and backfilled in sequence," International Journal of Geomechanics, vol. 15, no. 6, Article ID 04015005, 2015.

[28] A. Jahanbakhshzadeh, M. Aubertin, and L. Li, "A new analytical solution for the stress state in inclined backfilled mine stopes," Geotechnical and Geological Engineering, vol. 35, no. 3, pp. 1151-1167, 2017.

[29] Y. Ming-hui, X.-b. Dai, and M.-h. Zhao, "Calculation of earth pressure for limited soils with curved sliding surface," Rock and Soil Mechanics, vol. 38, no. 7, pp. 1-8, 2017.

[30] M. Wu, L. Li, C.-r. Wang, and F. Hui, "Comments on "Calculation of earth pressure for limited soils with curved sliding surface"," Rock and Soil Mechanics, vol. 39, no. 1, pp. 393-394, 2018.

[31] Y. Ming-hui, "Reply to the comments on "calculation of active earth pressure on finite-width fill under curved slip surface"," Rock and Soil Mechanics, vol. 39, no. 1, pp. 395-396, 2018.

[32] L. Li and M. Aubertin, "A modified solution to assess the required strength of exposed backfill in mine stopes," $\mathrm{Ca}$ nadian Geotechnical Journal, vol. 49, no. 8, pp. 994-1002, 2012.

[33] L. Li and M. Aubertin, "An improved method to assess the required strength of cemented backfill in underground stopes with an open face," International Journal of Mining Science and Technology, vol. 24, no. 4, pp. 549-558, 2014.
[34] P. Simms and M. Grabinsky, "Direct measurement of matric suction in triaxial tests on early-age cemented paste backfill," Canadian Geotechnical Journal, vol. 46, no. 1, pp. 93-101, 2009.

[35] E. Yilmaz, T. Belem, and M. Benzaazoua, "Effects of curing and stress conditions on hydromechanical, geotechnical and geochemical properties of cemented paste backfill," Engineering Geology, vol. 168, pp. 23-37, 2014.

[36] K. Pirapakaran and N. Sivakugan, "Arching within hydraulic fill stopes," Geotechnical and Geological Engineering, vol. 25, no. 1, pp. 25-35, 2007.

[37] N. Falaknaz, M. Aubertin, and L. Li, "Numerical investigation of the geomechanical response of adjacent backfilled stopes," Canadian Geotechnical Journal, vol. 52, no. 10, pp. 1507-1525, 2015.

[38] A. Jahanbakhshzadeh, M. Aubertin, and L. Li, "Analysis of the stress distribution in inclined backfilled stopes using closedform solutions and numerical simulations," Geotechnical and Geological Engineering, vol. 36, no. 2, pp. 1011-1036, 2018.

[39] P. Yang, L. Li, and M. Aubertin, "A new solution to assess the required strength of mine backfill with a vertical exposure," International Journal of Geomechanics, vol. 17, no. 10, Article ID 04017084, 2017.

[40] G. Liu, N. A. Li, X. Yang, and L. Guo, "Required strength estimation of a cemented backfill with the front wall exposed and back wall pressured," International Journal of Mining and Mineral Engineering, vol. 9, no. 1, pp. 1-20, 2018.

[41] L. Li, "Analytical solution for determining the required strength of a side-exposed mine backfill containing a plug," Canadian Geotechnical Journal, vol. 51, no. 5, pp. 508-519, 2014. 